\title{
Work-Family Boundary Management Profiles in Two Finnish Samples: A Person-oriented Approach
}

\author{
Ali Moazami-Goodarzi ${ }^{1}$, Johanna Rantanen ${ }^{2}$, Jari-Erik Nurmi ${ }^{1} \&$ Saija Mauno ${ }^{1,3}$ \\ ${ }^{1}$ Department of Psychology, University of Jyväskylä, yväskylä, Finland \\ ${ }^{2}$ Department of Teacher Education, University of Jyväskylä, yväskylä, Finland \\ ${ }^{3}$ School of Social Sciences and Humanities, University of Tampere, Tampere, Finland \\ Correspondence: Ali Moazami-Goodarzi, Department of Psychology, University of Jyväskylä, Ylistonmaentie 33, \\ 40500 Jyväskylä, Finland. E-mail: ali.moazami-goodarzi@jyu.fi
}

Received: September 4, 2015

Accepted: September 29, 2015

Online Published: October 22, 2015

doi:10.5430/ijba.v6n6p12

URL: http://dx.doi.org/10.5430/ijba.v6n6p12

\begin{abstract}
Background: The present study aims to identify different work-family boundary management profiles among Finnish employees, and examine how these relate to conflict between work and family or their mutual enrichment. Method: Participants from two samples, one consisting of university staff $\left(n_{1}=1,139\right)$ and another of nurses $\left(n_{2}=\right.$ 271 ), were asked to respond to an online survey concerning work-family boundary management, work-to-family enrichment, and work-to-family conflict scales.

Results: A cluster analysis identified three profiles in both samples: segmentors, integrators and favoring family over work in the university sample, and segmentors, integrators and favoring work over family in the nurse sample. In both samples integrators experienced a higher level of work-to-family enrichment and a lower level of work-to-family conflict in comparison to segmentors.

Conclusion: Individuals with a tendency to integrate work and family domains experience higher work to family enrichment and lower work to family conflict compared to those who separate work and family domains.

Keywords: work-family boundary management, domain flexibility, work-family enrichment, work-family conflict

\section{Introduction}

As moving between multiple roles is increasingly seen as a significant factor in people's lives, researchers have started to investigate how working adults navigate between such roles in the work and family domains (Rothbard \& Dumas, 2006). It has been suggested that individuals differ in the ways they manage boundaries between their work and family domains, and these are described as "boundary management styles" (Kreiner, Hollensbe, \& Sheep, 2009). Such styles have been defined as "the general approach an individual uses to demarcate boundaries and regulate attending to work and family roles" (Kossek, \& Lautsch, 2012, p. 155). Previous research has established that differences between individuals and the structure of their jobs will indeed affect their boundary management styles (Kossek, Lautsch, \& Eaton, 2005). But less is known about how boundary management styles are associated with specific work and family outcomes, such as work-family conflict and enrichment (Matthews \& Barnes-Farrell, 2010). Consequently, our study had two aims. First, we aim to identify boundary management profiles via a person-oriented analysis. Second, we aim to test how these profiles are associated with conflict and enrichment in the work-to-family context.
\end{abstract}

\subsection{Work-Family Boundary Management}

Different kinds of boundaries, such as physical, temporal or behavioral boundaries, serve to structure and determine the roles that a person has in different life domains (Matthews, Barnes-Farrell, \& Bulger, 2010). It has been suggested that these boundaries are not fixed, but are flexible according to the demands of each domain (Rosenzweig et al., 2011). Boundary-flexibility has thus been defined as the degree to which an individual has the capacity to contract or expand the domain boundary in response to demands from another domain (Clark, 2000). According to Matthews and Barnes-Farrell (2006), the flexibility of the family domain is positively associated with an increase in transitions from family to work roles (in response to increased work demands), while the flexibility of the work 
domain is positively associated with an increase in transitions from work to family roles (in response to increased family demands).

Matthews and Barnes-Farrell (2010) went on to extend this definition by suggesting that boundary-flexibility has two components. The flexibility-ability component describes the perceived ability to move from one boundary domain to another; so this means it easier to leave that domain to meet the demands of another when this component is high, and less likely when it is low (Matthews \& Barnes-Farrell, 2010). It's noteworthy that ability to alter boundaries is rooted in individuals' perception and might not necessarily have correspondence with reality. The other component is flexibility-willingness, describing an individual's motivation to move between various domains. High flexibility-willingness in individuals responding to family demands would thus mean there is a greater chance of them leaving the work domain to attend to family matters (Matthews et al, 2010). The flexibility-willingness component was developed in response to the proposition that individuals vary in their preferences for either integrating aspects of work and home or keeping them separate (Edwards \& Rothbard, 1999). The more an individual is willing and able to be flexible with regard to domain boundaries, the more blurred those boundaries will become, and this will, in turn, facilitate both physical and cognitive transitioning between domains (Desrochers, Hilton, \& Larwood, 2005).

\subsection{A Person-Oriented Approach to Work-Family Boundary Management}

A person-oriented approach identifies subgroups within a population according to a particular profile or pattern of variables characteristic of that set and shows how these patterns relate to adjustment (von Eye and Bergman, 2003; see Davidson, Gest, \& Welsh, 2010). It therefore provides a way of focusing on patterns of behavior that vary systematically between individuals. For this study, the patterns of behavior in question are work-family boundary management profiles.

Some previous studies on work-family boundary management have also used a person-centered approach. For example, Hartman (1997) has suggested that individuals simply vary in the degree to which they segment or integrate their work and family roles. High role segmentation occurs when the domains of home and work are considered as being separate, and physical space and time are designated a single purpose for segmented roles (Nippert-Eng, 1996a). In contrast, high role integration occurs when "no distinction exists between what belongs to 'home' or 'work' and when and where they are engaged" (Nippert-Eng, 1996a, p. 567). Work and family domains are not necessarily integrated or segmented to the same degree, however (Olson-Buchanan \& Boswell, 2006). The borders can be either stronger or weaker depending on the strength of the situation, the context, and the culture of the focal domain (Ashforth, Kreiner, \& Fugate, 2000; Clark, 2000).

Researchers have recently started to unpack this segmentation-integration continuum and give many different labels to these different configurations (Ammons, 2013; Bulger, Matthews \& Hoffman, 2007; Kossek \& Lautsch, 2008; Kossek et al., 2012; for a review see Allen, Cho, \& Meier, 2014). For example, Bulger and colleagues (2007) have found four distinct profiles to describe the boundaries that individuals place around their work and family which vary in flexibility and permeability. These consist of: (1) individuals who show high ability and willingness to be flexible with work and family domain boundaries and let them be permeable; (2) those who show high ability to be flexible with both boundaries, but are unwilling for them to be permeable; (3) those who show the average level of most of the boundary strength measures; and (4) individuals who report both high ability and willingness to be flexible with the work domain boundary, but not the family domain boundary. Likewise, Kossek and Lautsch (2012) suggested that there are three work-family boundary management styles that originate from individual boundary-crossing preferences (e.g., flexibility): (a) separators who distinguished work and family roles; (b) integrators who combined work and family roles; and, (c) alternating individuals who had clear periods of distinct integration and distinct separation. In a qualitative study, Ammons (2013) also found four different configurations based on preferred and actual boundaries that employees have: 1) individuals who kept work and family domains separate; 2) those who integrated work into family (eagerly or reluctantly), but with little to no integration of family into the work domain; 3 ) those who integrated family into work, but kept work from intruding into their personal lives; and 4) those who experienced work and family as one synergistic whole in terms of thoughts, behavior, and use of time and space.

The present study aims to identify boundary management profiles via a person-oriented analysis based on an individual's willingness (stated preference) and ability (enacted preference) to manage boundaries around work and family domains. Since the majority of the research has so far been conducted only in the United States, our study aims to extend our knowledge about boundary management in different contexts (Finland), in so far as there may be different personal, occupational and cultural priorities around work and family roles. 


\subsection{Work-Family Boundary Management and Work-Family Conflict and Enrichment}

It can be assumed that work-family boundary management styles are associated with an employee's own experience of work-family conflict and/or enrichment (Hecht \& Allen, 2009; Ilies, Wilson, \& Wagner, 2009). Work-family conflict is defined as "a form of inter-role conflict in which the role pressures from the work and family domains are mutually incompatible in some respect" (Greenhaus \& Beutell, 1985, p. 77). Meanwhile, work-family enrichment is defined as "the extent to which experiences in one role improve the quality of life in the other role" (Greenhaus \& Powell, 2006, p. 73). Although an ability to make an easy transition from one domain to another provides a means for decreasing the conflict between roles (Ashforth et al., 2000), current empirical research has shown that increasing the transition overall between roles can nevertheless result in higher conflict between those roles (Desrochers et al., 2005; see Matthews \& Barnes-Farrell, 2010).

Chen, Powell, and Greenhaus (2009) found that the existing fit between an individual's desire for segmentation and organizational policies was actually negatively associated with work-to-family conflict and positively associated with work-to-family enrichment or "positive spillover". Similarly, Li, Miao, Zhao, and Lehto (2013) showed that setting a clear border around the work domain and reducing the level of integration of work and family domains was positively related to work-life balance. In addition, Desrochers and colleagues (2005) showed that a higher integration of work and family was positively associated not only with the number of hours worked both at home and work, but also with distractions while working at home, and with work-family conflict. Similarly, Kossek, Lautsch and Eaton (2006) found that work-family boundary management styles which scored higher on integration were positively related to family-work conflict. Meanwhile, Ilies, et al. (2009) found that the extent to which employees integrate their work and family roles is positively associated with the strength of daily job satisfaction spillover into negative and positive affects at home. Taken together, these four studies therefore suggest that segmentation rather than integration is beneficial for a healthy work-family balance, in other words where there is high work-family enrichment and low work-family conflict (Frone, 2003).

It is particularly interesting that all four of these studies have used a variable-oriented approach. In this approach, associations between specific variables are examined, rather than use the individuals themselves, and these are considered random and interchangeable indicators of behavior (von Eye, Bogat, \& Rhodes, 2006). In contrast, this study uses a person-centered approach to establish different work-family boundary management profiles, with regard to the position of individuals on an integration-segmentation continuum.

\subsection{The Present Study}

The first aim of the present study was to investigate whether there exist homogeneous groups of employees, each with a distinct profile to their style of work-family boundary management. To identify such groups, a person-oriented approach via cluster analysis was used. The criteria variables in the cluster analysis were: 1) work boundary-flexibility-ability, 2) work boundary-flexibility-willingness, 3) family boundary-flexibility-ability, and 4) family boundary-flexibility-willingness (Matthews and Barnes-Farrell, 2006). We assumed that this range of boundary management styles provides sufficient information on where individuals would be placed on the segmentation-integration continuum. In line with earlier findings (Bulger et al., 2007; Matthews et al., 2010), and previous theories regarding boundary management styles (Ashforth et al., 2000; Clark, 2000), we hypothesize that at least two profiles will emerge from our data sets (H1). These profiles will be segmentors, who separate work and family domains; and integrators, who merge the work and family domains.

Our second research aim was to then examine the extent to which the two boundary management profiles we had identified differed in terms of work-to-family conflict and enrichment. On the basis of previous studies (Chen et al., 2009; Li et al., 2013), our hypothesis (H2) was that the segmentors would report less work-to-family conflict (H2a) and greater work-to-family enrichment $(\mathrm{H} 2 \mathrm{~b})$ than the integrators.

As Matthews and Barnes-Farrell's "domain flexibility measure" (2010) has not yet been validated among Finnish employees, we also tested this instrument's construct validity, to make sure that it would be a reliable and valid measure in this particular context. Our hypothesis (H3) was that the four-factor theoretical structure that Matthews and Barnes-Farrell reported in 2010 would be replicated in our samples - namely-flexibility-ability and flexibility-willingness as regards work boundaries and family boundaries.

\section{Method}

\subsection{Participants and Procedure}

University sample. The first sample is part of a larger study on university employees $\left(N_{\text {University } 1}=666 ; N_{\text {University } 2}=\right.$ 644). Data was gathered through an online survey in 2009 that targeted academic staff, and administrative and 
technical personnel employed in two universities in Central Finland. The participants consisted of professors, lecturers, senior teaching assistants, researchers, and PhD students. All employees at both the universities who were appointed to work for at least $50 \%$ of a normal full-time work schedule were invited to complete an online questionnaire about their health and well-being-both at work and in general. In total, we received 2137 (out of 4508) responses after two reminders, yielding a response rate of $48 \%$ (see Mauno, De Cuyper, Tolvanen, Kinnunen, \& Mäkikangas, 2014).

Because the present study focused on managing boundaries between work and family, the sample was restricted to the sub-sample of university employees who had some family demands; having partner or children under 18 ( $n=$ 1139). Of these participants, $775(68 \%)$ were women, $364(32 \%)$ men, and their mean age was 42.8 years $(S D=$ 10.5). Sixty-eight percent of the participants had at least one child under the age of 18 living with them. The average length of job tenure was 20.06 years $(S D=10.9)$, and the average length of a working week for the sample was 40.52 hours $(S D=8.56)$.

Nurses. The second sample $(n=301)$ was gathered via an online questionnaire in spring 2009 from nurses in one health care district in Finland. As we did not have their email addresses, both the invitation to participate and a link to the questionnaire was posted on the health care district's intranet.

In this sample, the data analysis was again restricted to individuals who were, at the time of the study, living with a partner and/or children $(n=271)$. Of these participants, $243(90 \%)$ were female and $28(10 \%)$ men, and their mean age was 46.8 years $(S D=10.2)$. Seventy-two percent of the participants had at least one child under the age of 18 living with them. The average length of job tenure was 20.34 years $(S D=10.2)$, and the average working week was 38.48 hours $(S D=4.10)$.

\subsection{Measures}

Domain flexibility. Participants' perception of work-family boundary-flexibility was evaluated using the domain flexibility scale, as established by Matthews and Barnes-Farrell (2010). The scale consisted of four subscales: 1) work flexibility-ability (WFA), 2) work flexibility-willingness (WFW), 3) family flexibility-ability (FFA), and 4) family flexibility-willingness (FFW). These subscales then each had four items-rated from $1=$ strongly disagree to 7 = strongly agree (for reliabilities see table 1). Below are listed examples of each of these items.

1) "While at work, I can stop what I am doing to meet responsibilities related to family and my personal life responsibilities" (WFA).

2) "I am willing to take time off from work to deal with my family and personal life responsibilities" (WFW).

3) "My family and personal life responsibilities would not prevent me from going into work early if the need arose" (FFA).

4) "I am willing to cancel plans with my friends and family to deal with work related responsibilities" (FFW).

Work-family enrichment. Work-to-family enrichment was measured by four items derived from the "enrichment scale" developed and validated by Carlson, Kacmar, Wayne, and Grzywacz (2006, e.g., "My involvement in my work makes me feel happy and this helps me to be a better family member"). The response scale ranged from 1 = strongly disagree to $7=$ strongly agree (for reliabilities see Table 1 ).

Work-family conflict. We also used four items to measure work-to-family conflict derived from the scale developed by Carlson, Kacmar, and Williams (2000) (e.g., "The time I must devote to my job keeps me from participating equally in household responsibilities and activities"). The response scale for this also ranged from $1=$ strongly disagree to 7 = strongly agree (for reliabilities see table 1).

Background information. Participants were also asked questions about their age, gender, weekly working hours, how long they had been in their job, and the ages of their children. These were then used as control factors in certain analyses.

\subsection{Analytic Strategy}

Firstly, the construct validity of the domain flexibility scale was established by examining its factor structure using confirmatory factor analysis (CFA). We relied on several fit indices to ascertain the model fit, including the Tucker Lewis index (TLI), the comparative fit index (CFI), the root mean square error of approximation (RMSEA) and the standardized root mean square residual (SRMR). "Good fit", in terms of CFI and TLI values means greater than .90, while RMSEA values should be no more than .06, and SRMR less than .08 (Hu \& Bentler, 1999). We also investigated whether the four-factor structure was invariant across both samples. Due to the sample of university 
staff being so large, we randomly chose only $20 \%$ of the nurse participants $(\mathrm{n}=301)$ to test for measurement invariance.

Next, we conducted a cluster analysis to identify the various different profiles of participants who were homogenous in terms of boundary management scores. The two-stage cluster analysis, in SPSS 21.0 first identifies the total number of profiles (clusters) and then classifies them using a nonhierarchical procedure. In the pre-clustering stage, cases are divided into small sub-clusters. These sub-clusters are then further arranged into the desired or pre-defined number of clusters (see Facca \& Allen, 2011). By default, to determine the optimal number of clusters, SPSS uses an algorithm which is based, in part, on Bayesian (BIC) information criteria loss.

Finally, analyses of covariance (ANCOVAs) were conducted to test for profile differences between prime examples of work-to-family conflict and enrichment, and the difference between pairs of such opposites were also tested using Bonferroni correction. Control variables used in these analyses were age, gender, having a child under the age of 18 , length of tenure in a job, and hours of work per week.

\section{Results}

Table 1 shows the means, standard deviations, reliabilities, and bivariate correlation of the variables.

Table 1. Means (M), Standard Deviations (SD), reliabilities and Bivariate Correlations of Study Variables

\begin{tabular}{|c|c|c|c|c|c|c|c|c|c|c|c|c|c|c|c|c|c|}
\hline Variables & M & $\mathrm{SD}$ & $\alpha$ & 1 & 2 & 3 & 4 & 5 & 6 & 7 & 8 & 9 & 10 & 11 & M & SD & $\alpha$ \\
\hline 1. Work & 5.37 & 1.17 & $(.84)$ & - & $.54 * *$ & $.27 * *$ & $.21 * *$ & $.24 * *$ & $-.27 * *$ & $-.15^{*}$ & -.04 & $-.12 *$ & .07 & .01 & 3.98 & 1.38 & $(.80)$ \\
\hline \multicolumn{18}{|l|}{ Flexibility-ability } \\
\hline 2. Work & 5.34 & 1.10 & $(.79)$ & $.73 * *$ & - & .07 & .07 & $.22 * *$ & -.11 & .16 & $.15^{*}$ & -.05 & $.12 *$ & -.07 & 4.65 & 1.12 & $(.66)$ \\
\hline \multicolumn{18}{|l|}{ Flexibility- willingness } \\
\hline 3. Family & 4.58 & 1.28 & $(.71)$ & $.13 * *$ & -.01 & - & $.65 * *$ & $.17 * *$ & $-.15^{*}$ & -.01 & -.00 & .05 & .01 & $.17^{* *}$ & 3.93 & 1.37 & $(.80)$ \\
\hline \multicolumn{18}{|l|}{ Flexibility-ability } \\
\hline 4. Family & 3.64 & 1.32 & $(.81)$ & .01 & -.07 & $.61 * *$ & - & $.30 * *$ & -.10 & $.35^{* *}$ & -.04 & -.07 & .00 & .09 & 2.75 & 1.24 & $(.84)$ \\
\hline \multicolumn{18}{|l|}{ Flexibility-willingness } \\
\hline 5. Work-Family & 4.30 & 1.23 & $(.84)$ & $.14^{* *}$ & .05 & $.16^{* *}$ & $.17 * *$ & - & $-.38 * *$ & $.27 * *$ & -.05 & -.11 & .04 & .00 & 4.43 & 1.12 & $(.84)$ \\
\hline \multicolumn{18}{|l|}{ Enrichment } \\
\hline 6. Work-Family & 3.55 & 1.29 & $(.79)$ & $-.28 * *$ & $-.16^{* *}$ & $-.07 *$ & .09 & $-.32 * *$ & - & .11 & -.00 & .09 & .04 & -.00 & 4.43 & 1.12 & $(.77)$ \\
\hline \multicolumn{18}{|l|}{ Conflict } \\
\hline 7. Age & 43.86 & 10.56 & & $-.20 * *$ & $-.21 * *$ & $.13 * *$ & $.08 * *$ & $-.07 * *$ & .10 & - & $-.19 * *$ & $-.42 * *$ & .02 & .07 & 46.79 & 10.16 & \\
\hline 8. Gender ${ }^{a}$ & 1.31 & 0.46 & & $.06^{*}$ & $.07 *$ & -.02 & .04 & $-.10 * *$ & .05 & $.07 *$ & - & $.22 * *$ & .05 & .03 & 1.10 & 0.30 & \\
\hline 9. Child under $18^{\mathrm{b}}$ & 1.31 & 0.46 & & $-.07 *$ & $.14 * *$ & $.31 * *$ & $.15^{* *}$ & -.04 & -.05 & $.67 * *$ & -.02 & - & .00 & .07 & 1.25 & 0.43 & \\
\hline 10. Tenure & 20.06 & 10.94 & & $-.20 * *$ & $-.19 * *$ & $.15^{* *}$ & $.10 * *$ & $.09 * *$ & -.02 & $.93 * *$ & $.08 * *$ & $.65 * *$ & - & -.08 & 20.34 & 10.16 & \\
\hline 11. Weekly work hours & 40.68 & 9.22 & & -.04 & -.04 & $.13^{* *}$ & $.12 * *$ & -.02 & $.26^{* *}$ & $.06^{*}$ & $.13 * *$ & .03 & .05 & - & 38.52 & 4.25 & \\
\hline
\end{tabular}

Note. Measures of university and nurse samples are above and below the diagonal, respectively. Internal consistency estimates, that is, reliabilities are reported in parentheses.

${ }^{\mathrm{a}} 1$ = Female, 2 = Male; ${ }^{\mathrm{b}} 0=$ Yes I have a child under $18,1=$ No I don't have; ${ }^{*} p<.05 . * * p<.01$.

\subsection{University Sample}

Older staff tended to set a clear border around their work domain and blur the border around their family domain. Women showed a lower level of WFA and WFW $(\mathrm{t}=2.51, \mathrm{p}<.01 ; \mathrm{t}=2.69, \mathrm{p}=.007$, respectively). They also worked more hours $(\mathrm{t}=4.74, \mathrm{p}<.001)$, had a lower length of tenure in their jobs $(\mathrm{t}=2.92, \mathrm{p}<.001)$, and experienced a higher level of work-to-family enrichment. Results also revealed that while length of tenure was negatively related to WFA and WFW and positively related to FFA and FFW, it was also positively related to a higher level of work-to-family enrichment. Likewise, having a child under the age of 18 was positively related to WFW, FFA and FFW, but negatively associated with WFA. Moreover, those who worked more hours were more 
likely to be flexible with the borders surrounding their family domains and to experience work-to-family conflict. Meanwhile, the ability to set a more permeable border around both work and family domains was positively associated with work-to-family enrichment and negatively associated with work-to-family conflict.

\subsection{Nurse Sample}

There was a negative correlation between age and ability to set a flexible border around work, but older nurses were more motivated to blur borders around the family domain. Women in this sample were more motivated to be flexible with the borders surrounding work $(\mathrm{t}=2.43, \mathrm{p}=.02)$, and nurses who worked more hours saw themselves as more able to be flexible with the borders around their family domain. In addition, nurses who had been in their job longer were more willing to place a flexible border around their work domain, and experienced a high level of work-to-family enrichment $(\mathrm{t}=3.62, \mathrm{p}<.001)$, while having a child under 18 was negatively associated with one's ability to set a flexible border around work. Overall, flexibility-ability and flexibility-willingness in both domains proved to be positively correlated with work-to-family enrichment, whereas a perceived inability to place a more flexible border around work and family domains proved to be associated with greater work-to-family conflict.

\subsection{Confirmatory Factor Analysis}

University sample. CFA results revealed that the correlated four-factor model used, i.e., work-flexibility-ability (WFA), work-flexibility-willingness (WFW), family-flexibility-ability (FWA) and family-flexibility-willingness (FFW), showed a satisfactory fit in the university sample $\left(\mathrm{chi}^{2} / d f=3.22 ; \mathrm{CFI}=.90 ; \mathrm{TLI}=.88 ; \mathrm{RMSEA}=.08\right.$; SRMR $=.06)$. Modification indices suggested, however, that estimating the associations of measurement errors between WFW item 3 and WFW item 4, and between WFA item 3 and WFW item 3 would substantially improve the fit of the model $\left(\mathrm{chi}^{2} / d f=2.65 ; \mathrm{CFI}=.93\right.$; TLI $=.91$; RMSEA $=.07$; SRMR $\left.=.05\right)$. After these estimations had been made, the model was significantly better than original model $\left(\Delta c h i^{2}(2)=61, p<.001\right)$. With the new model, the correlations between the four factors showed that the within-life domain correlations (i.e., between ability and willingness) were now higher than the cross-life domain correlations (i.e., between life and work). In other words, $r$ between WFA and WFW $=.73$ and $r$ between FFA and FFW $=.61$, whereas $r$ between FFA and WFA $=.13$, and $r$ between FFW and WFW $=-.07$.

Nurse sample. We ran a similarly correlated four-factor model for the nurse sample, but the fit of the model was not acceptable $\left(\mathrm{chi}^{2} / d f=3.98 ; \mathrm{CFI}=.88 ; \mathrm{TLI}=.85 ; \mathrm{RMSEA}=.08\right.$; SRMR $\left.=.07\right)$. So on the basis of modification indices, we estimated the measurement errors between WFW item 3 and WFW item 4, between WFA item 3 and WFW item 3, and between FFA item 1 and FFW item 3. After these estimations the model showed a better fit $\left(\mathrm{chi}^{2} / d f=2.47\right.$; CFI $=.92 ;$ TLI $=.90 ;$ RMSEA $=.07$; SRMR $\left.=.06\right)$ than the original model $\left(\Delta c h i^{2}(3)=303, p\right.$ $<.001)$. As in the university sample, the within-life domain correlations here were higher than the cross-life domain correlations; In other words, $r$ between WFA and WFW $=.54$, and $r$ between FFA and FFW $=.65$, whereas $r$ between FFA and WFA $=.27$, and $r$ between FFW and WFW $r=.07$.

We also explored the measurement invariance of the correlated four-factor structure across the two samples by comparing the freely estimated model to the constrained model with a Satorra-Bentler scaled chi-square difference test (Satorra \& Bentler, 2001). Factor loadings were allowed to vary across the samples in the freely estimated model, whereas factor loadings were made equal across the samples in the constrained model. Results indicated invariant factor loadings among the measurement models $\left(\Delta \chi^{2}(12)=19.01, p<.08\right)$.

\subsection{Identification of the Boundary Management Profiles and Differences between Them in Background Variables}

University sample. In order to identify homogenous groups of participants differing in their boundary management profiles from other groups, SPSS's two-step clustering analysis was conducted, with the four work-family boundary-flexibility variables used as criteria variables. These variables were standardized prior to the cluster analysis, and the number of clusters was determined on the basis of three criteria: BIC value (the Bayesian information criterion), a theoretical interpretation of the clusters, and the number of cases in each cluster. The two-step clustering method suggested that a three cluster solution would best describe the data, even though a four cluster solution had the lowest BIC (902.65), when compared to one (1455.87), two (1203.80), or three (978.71) cluster solutions. The three cluster solution was eventually chosen, because the change in the BIC (-225.8) and ratio of distance measures (2.16) in it were both greater. The means and standard deviations for the three cluster solution are thus reported in table 2, and its demographic description in Table 3. 
Table 2. Cluster Membership Means, Standard Deviation, and Analysis of Variance Results

\begin{tabular}{|c|c|c|c|c|c|c|c|c|c|c|c|c|c|c|c|c|}
\hline & \multicolumn{8}{|c|}{ University sample } & \multicolumn{8}{|c|}{ Nurse sample } \\
\hline & \multicolumn{2}{|c|}{$\mathrm{C} 1_{\text {Segmentor }}$} & \multicolumn{2}{|c|}{$\begin{array}{l}\mathrm{C} 2 \text { Favoring } \\
\text { family over work }\end{array}$} & \multicolumn{2}{|c|}{$\mathrm{C} 3_{\text {Integrators }}$} & & & \multicolumn{2}{|c|}{$\mathrm{C} 1_{\text {Segmentor }}$} & \multicolumn{2}{|c|}{$\begin{array}{l}\mathrm{C} 2_{\text {Favoring work }} \\
\text { over family }\end{array}$} & \multicolumn{2}{|c|}{$\mathrm{C} 3_{\text {Integrators }}$} & & \\
\hline & $\mathrm{n}=4$ & & $\mathrm{n}=3$ & & $\mathrm{n}=2$ & & & & $\mathrm{n}=85$ & & $\mathrm{n}=11$ & & $\mathrm{n}=7$ & & & \\
\hline & $\mathrm{M}$ & $S D$ & $\mathrm{M}$ & $S D$ & $\mathrm{M}$ & $S D$ & $F^{a}$ & $\eta \mathrm{p}^{2}$ & $\mathrm{M}$ & $S D$ & $\mathrm{M}$ & $S D$ & $\mathrm{M}$ & $S D$ & $\mathrm{~F}^{\mathrm{a}}$ & $\mathrm{yp}^{2}$ \\
\hline $\begin{array}{l}\text { Work-flexibility } \\
\text { ability }\end{array}$ & -.74 & .82 & $.56^{\mathrm{a}}$ & .54 & $.61^{\mathrm{a}}$ & .50 & $544.52 * *$ & .49 & -.51 & .81 & $-.35 \mathrm{a}$ & .75 & $1.18^{\mathrm{a}}$ & .48 & $133.90^{* *}$ & .50 \\
\hline $\begin{array}{l}\text { Work-flexibility } \\
\text { willingness }\end{array}$ & -.78 & .76 & $.65^{\mathrm{a}}$ & .51 & $.55^{\mathrm{a}}$ & .58 & $650.43^{* *}$ & .53 & -.33 & .94 & $-.37^{\mathrm{a}}$ & .82 & $1.00^{\mathrm{a}}$ & .58 & $74.05^{* *}$ & .35 \\
\hline $\begin{array}{l}\text { Family- flexibility } \\
\text { ability }\end{array}$ & -.11 & .86 & -.61 & .09 & .89 & .53 & $269.49 * *$ & .32 & -1.04 & .54 & .44 & .64 & .53 & .96 & $133.63 * *$ & .50 \\
\hline $\begin{array}{l}\text { Family-flexibility } \\
\text { willingness }\end{array}$ & .02 & .82 & -.76 & 0.65 & 1.02 & .66 & $466.45^{* *}$ & .45 & .91 & .42 & .40 & .77 & .44 & 1.11 & $81.56^{* *}$ & .38 \\
\hline
\end{tabular}

Note: All means reported are z-scores. Across rows, means that share subscripts do not differ significantly from one another, otherwise they are significantly different. Results for mean are estimated by Scheffe's t-test.

$C 1=$ Segmentors; $C 2=$ Favoring family over work; $C 3=$ Integrators; ${ }^{a} d f$ are 3, 328 for Academic sample and 2, 268 for Nurse Sample; $* * p<.01$.

The three profiles identified were: segmentors $(n=480,42 \%)$, favoring family over work $(n=394,35 \%)$ and integrators $(n=260,23 \%)$. Segmentors were characterized by low levels of WFA and WFW, but average levels of FFA and FFW. Compared with the other two clusters, however, they had held their jobs for longer $(\mathrm{F}(2,1116)=$ $30.98, \mathrm{p}<.001)$.

The favoring family over work profile comprised of individuals who scored low on FFA and FFW, but high on WFA and WFW. These individuals seemed to separate family from work yet still be able to integrate work with family. This was also the youngest profile $(\mathrm{F}(2,1116)=30.98, \mathrm{p}<.001)$, and the majority of its members had a child who was under 18 years old $(\mathrm{F}(2,813)=17.83, \mathrm{p}<.001)$. In addition, they worked fewer hours per week $(\mathrm{F}(2,1126)=$ $4.00, \mathrm{p}=.018)$, and had held their job for a shorter time $(\mathrm{F}(2,1116)=30.98, \mathrm{p}<.001)$ than individuals in the two other clusters.

Integrators exhibited high levels of FFW, FFA, WFW and WFA which places them on the high integration end of the segmentation-integration continuum. The members of this profile also worked more hours per week $(\mathrm{F}(2,1126)$ $=4.00, \mathrm{p}=.018)$ than other profiles.

Nurse sample. The two-step clustering method suggested that a three cluster solution described the nurse data best. Although, as in the university sample, the four cluster solution had a lower BIC (902.65) than the three (627.31), the three cluster solution was eventually chosen, because the change in the BIC (-55.64) and ratio of distance measures (1.89) in it were both greater. As with the university sample too, the means and standard deviations for this three cluster solution are reported in table 2, and the demographic description in table 3.

The three profiles in this sample were segmentors ( $n=85,32 \%)$, favoring work over family $(n=115,42 \%)$, and integrators $(n=71,26 \%)$. Segmentors scored low in both work-flexibility measures as well as FFA, but high on FFW. They were also younger and worked fewer hours per week $[\mathrm{F}(2,265)=4.37, \mathrm{p}=.014]$ than the other two clusters (see table 3).

The integrators achieved high scores in both family-flexibility domains, and medium scores in both work-flexibility domains. This places them near to the integration end of the segmentation-integration continuum. In comparison with the two other clusters, more of them had a permanent job $[\mathrm{F}(2,266)=9.86, \mathrm{p}<.001]$ and a child under $18[\mathrm{~F}(2,200)$ $=6.47, \mathrm{p}=.002]$.

Meanwhile, the favoring work over family profile was characterized by low scores in both work-flexibility domains and average scores in both family-flexibility domains. The nurses in this profile tended to have a flexible border around their family but not work, and they were generally older than integrators $[\mathrm{F}(2,263)=10.36, \mathrm{p}<.001]$, had 
been in their job the shortest amount of time $[\mathrm{F}(2,266)=9.85, \mathrm{p}<.001]$, and worked the most hours per week [F $(2$, $265)=4.37, \mathrm{p}=.014]$.

Table 3. Demographics of the work-family boundary management profiles. Means (SDs) or percentage

\begin{tabular}{lllllll}
\hline & \multicolumn{5}{l}{ University sample } & \multicolumn{3}{l}{ Nurse sample } \\
\hline & $\mathbf{C 1}$ & $\mathbf{C 2}$ & $\mathbf{C 3}$ & $\mathbf{C 1}$ & $\mathbf{C 2}$ & $\mathbf{C 3}$ \\
& $\mathrm{n}=480$ & $\mathrm{n}=394$ & $\mathrm{n}=260$ & $\mathrm{n}=85$ & $\mathrm{n}=115$ & $\mathrm{n}=71$ \\
\hline $\begin{array}{l}\text { Age } \\
\text { Gender }\end{array}$ & $46.37(9.90)$ & $40.75(9.74)$ & $43.79(11.69)$ & $42.80(8.55)$ & $48.83(10.92)$ & $48.40(9.41)$ \\
female & & & & & \\
male & $73 \%$ & $65 \%$ & $65 \%$ & $88 \%$ & $90 \%$ & $90 \%$ \\
Having child under 18 & $27 \%$ & $35 \%$ & $35 \%$ & $12 \%$ & $10 \%$ & $10 \%$ \\
Yes & & & & & & $79 \%$ \\
No & $63 \%$ & $81 \%$ & $59 \%$ & $76 \%$ & $28 \%$ & $21 \%$ \\
Weekly work hours & $37 \%$ & $19 \%$ & $41 \%$ & $24 \%$ & $28 \%$ & $37.42(4.34)$ \\
Tenure & $40.64(8.22)$ & $39.67(7.88)$ & $41.58(9.93)$ & $38.76(4.65)$ & $39.10(3.38)$ & \\
\hline
\end{tabular}

Note: $C 1=$ Segmentors; $C 2=$ Favoring family over work; $C 3=$ Integrators.

\subsection{Summary of the Differences between the Identified Boundary Management Profiles}

The integrators in the university sample scored higher in all four criteria variables than those in the nurse sample $(\mathrm{WFA}, t(330)=6.22, p<.001$; WFW, $t(330)=2.36, p<.019$; FFA, $t(330)=9.93, p<.001$; FFW, $t(330)=12.93$, $p<.001)$. Similarly, the segmentors in the university sample scored significantly higher than the nurse segmentors in both family-flexibility domains (FFA, $t(563)=15.94, p<.001$; FFW, $t(563)=17.10, p<.001$ ) and in work-flexibility ability (WFA, $t(563)=9.95, p<.001$ ), but there was no significant difference between them in the willingness domain (WFW, $t(563)=1.50, p<.001)$. Unlike the other two profiles, however, the third profile was completely different in both samples. In the university sample, individuals from this profile were more flexible about work boundaries (WFA, $t(507)=32.41 p<.001$; WFW, $t(507)=25.90 p<.001$ ) but clearer about family boundaries, whereas in the nurse sample it was the inverse: they tended to set a flexible border around their family domains $(\mathrm{FFA}, t(507)=-5.73 p<.001$; FFW, $t(507)=-6.26 p<.001)$, but a vivid border around their work domains.

3.6 Differences between the Boundary Management Profiles in Work-to-Family Enrichment and Work-to-Family Conflict

University staff. The results showed that the main effects of work-family boundary management profiles were significant for both work-to-family enrichment $[\mathrm{F}(2,752)=12.54, \mathrm{p}<.000]$ and work-to-family conflict $[\mathrm{F}(2,752)=$ $12.14, \mathrm{p}<.000]$, after controlling for age, gender, having children under 18 , length of tenure and weekly working hours as covariates (see table 4). Post hoc comparisons using Bonferroni correction showed that those in the integrators profile experienced a significantly higher level of work-to-family enrichment $(\mathrm{M}=4.68, \mathrm{SD}=1.23)$ than either those in the favoring family over work $(\mathrm{M}=4.15, \mathrm{SD}=1.25)$, or segmentors profiles $(\mathrm{M}=4.22, \mathrm{SD}=1.17)$. In turn, those in the segmentors experienced a significantly higher level of work-to-family conflict $(\mathrm{M}=3.80, \mathrm{SD}=$ $1.29)$ than either those in the favoring family over work $(\mathrm{M}=3.25, \mathrm{SD}=1.21)$ or integrators profiles $(\mathrm{M}=3.45, \mathrm{SD}$ $=1.31$ ).

Nurses. The results of the ANCOVA showed that the work-family boundary management profiles varied significantly as regards work-to-family enrichment $[\mathrm{F}(2,255)=7.19, \mathrm{p}<.001]$ and work-to-family conflict $[\mathrm{F}(2,255)$ $=3.22, \mathrm{p}<.04]$, after controlling for age, gender, having children under 18, length of tenure, and weekly working hours as covariates (see table 4). Post hoc multiple comparisons using Bonferroni correction showed that those in the segmentors profile reported a significantly lower level of work-to-family enrichment $(\mathrm{M}=4.10, \mathrm{SD}=1.11)$ than those in the integrators $(\mathrm{M}=4.95, \mathrm{SD}=1.00)$. Meanwhile, those in the segmentors experienced a significantly 
higher level of work-to-family conflict $(\mathrm{M}=3.98, \mathrm{SD}=1.27)$ than those in the favoring work over family $(\mathrm{M}=3.68$, $\mathrm{SD}=1.13)$ and integrators profiles $(\mathrm{M}=3.32, \mathrm{SD}=1.21)$.

Table 4. ANCOVA results for work-family enrichment and work-family conflict in university and nurse samples

\begin{tabular}{lllllllll}
\hline & \multicolumn{2}{l}{ Work-family enrichment } & \multicolumn{5}{l}{ Work-family conflict } \\
\hline & $\mathrm{F}$ & $\mathrm{p}$ & $\mathrm{df}$ & $\mathrm{yp}^{2}$ & $\mathrm{~F}$ & $\mathrm{p}$ & $\mathrm{df}$ & $\mathrm{yp}^{2}$ \\
\hline Work-family boundary management styles & 12.36 & .000 & 2 & .032 & 11.21 & .000 & 2 & .029 \\
\hline & 7.19 & .001 & 2 & .075 & 3.22 & .04 & 2 & .035 \\
\hline Age & 1.06 & .30 & 1 & .001 & 0.25 & .61 & 1 & .000 \\
\hline & 1.89 & .17 & 1 & .011 & 2.18 & .14 & 1 & .012 \\
\hline Gender & 18.17 & .000 & 1 & .024 & 1.76 & .18 & 1 & .002 \\
\hline & 0.04 & .83 & 1 & .000 & 0.03 & .96 & 1 & .000 \\
\hline Work per week & 0.74 & .38 & 1 & .001 & 63.52 & .000 & 1 & .078 \\
\hline Tenure & 0.30 & .58 & 1 & .002 & 0.30 & .58 & 1 & .002 \\
\hline & 0.19 & .65 & 1 & .000 & 0.08 & .77 & 1 & .000 \\
\hline Having child under 18 & 1.59 & .20 & 1 & .009 & 1.83 & .17 & 1 & .010 \\
\hline & 0.11 & .73 & 1 & .000 & 0.96 & .32 & 1 & .001 \\
\hline
\end{tabular}

Note: $\eta p^{2}=$ Partial eta squared values are suggestive of significant effect size. Measures of nurses sample are in the second line.

\section{Discussion}

The present study aimed to identify groups of employees who would show different work-family boundary management style profiles. The two different Finnish samples chosen were university staff and nurses. Cluster analysis identified three profiles, two of which were closely similar in both the samples-segmentors and integrators. Segmentors were characterized by a low level of work-flexibility willingness and ability, but an average level of family-flexibility willingness and ability. Meanwhile, integrators were characterized by high levels of willingness and ability in both family-flexibility and work-flexibility. These results were consistent with H1 of our hypotheses, and were in line with previous studies (Ashforth et al., 2000; Bulger et al., 2007; Clark, 2000; Matthews et al. 2010). However, the third profile differed in each sample. Among university employees, it was described as favoring family over work, while among nurses it was called favoring work over family. This was because the university employees scored low on family-flexibility ability and willingness but high on ability and willingness to blur their work domain boundary for family needs; while, inversely, nurses scored low on work-flexibility ability and willingness, but high on ability and willingness to blur their family domain boundary.

Although two similar kinds of profiles were found in both samples (segmentors and integrators), they showed somewhat different characteristics in each sample. In both samples, segmentors reported lower scores in both work-flexibility domains (willingness and ability), but with regard to family-flexibility they differed. Whereas in the university sample segmentors showed neither the willingness nor ability to be flexible about the boundaries they set around their family domain, the nurse segmentors showed a willingness to be so, even if they felt they were not really able to. In both samples, integrators showed high levels of flexibility in all four domains, which implies that they were both willing and able to integrate work and family domains in a roughly equal and symmetrical fashion, that is, in both directions from work to family and vice versa. The difference between the two samples was that while integrators among university staff were more flexible around their work borders, among the nurses they were more flexible regarding family.

The third profile in the university sample was described as favoring family over work. This was because members of this profile scored low on both the family-flexibility domains but high on both willingness and ability to be flexible with work boundaries. In other words, although they tended to be flexible with work if family demands required it, 
family life tended to remain separate so that work demands would not impinge on it. In fact, in this respect, members of this profile were very similar to integrators regarding their work-flexibility domains.

The third profile in the nurse sample was described as favoring work over family. This was because members of this profile scored low on both work-flexibility domains, but high on both ability and willingness to be flexible with their family domain boundaries. In other words, although they tended to be flexible with family if work required it, their work domain remained separate so that family demands would not impinge on it. In this respect, they were acting like segmentors in both work domains, and like integrators in the family domains.

One possible explanation for the different results between the university and nurse samples with regard to work and family lives comes down to the nature of their jobs (Kossek, Baltes, \& Matthews, 2011). For example, university staff has more flexible work arrangements and, as they rely on information technology to get a lot of their work done, they can do this remotely. This simultaneously gives them more freedom with work schedules, but also encourages the blurring of work and family boundaries. Meanwhile, as most nurses are required to work in physical proximity to their patients, and in shifts which strictly delineate worktimes, family demands must wait.

In addition, individuals may have their own predilections that shape their boundary management styles and preferences (Kreiner et al., 2009). Regardless of the nature of their work, segmentors like to keep their personal lives separate from work, while integrators attempt to merge them.

Overall, our findings provide support for a segmentation-integration continuum (Ashforth et al., 2000; Clark, 2000), which suggests that people can be placed somewhere on a continuum from integration at one end, to segmentation of work and family roles at the other, based on how they manage or demarcate boundaries between these. Those who set flexible borders are at the integration end, while those who cannot or who find it hard to do so, are at the segmentation end of continuum. The profiles favoring family over work and favoring work over family are located somewhere between the two ends. Some of our findings concerning the profiles (i.e., integrators in both samples and favoring work over family) were fairly consistent with the profiles found by Bulger and colleagues (2007). They found four different profiles based on the level of perceived ability and willingness in setting boundaries around the domains of work and personal life, and on the level of permeability of those boundaries: (1) individuals who are able and willing to be flexible with permeable work and family domain boundaries; (2) individuals who are able but unwilling to be flexible with work and family domain boundaries, nor allow their permeability; (3) individuals who report average ability and willingness with regard to boundary strength measures; and (4) individuals who are able and willing to be flexible with the work domain boundary, but not the family domain boundary. In the present study, however, we did not use the construct of permeability in our data, which makes our results harder to compare to this. Moreover, favoring work over family and favoring family over work profiles were in somehow consistent respectively with the "above and beyond" and "enhance family" profiles found by Ammons (2013) who interviewed 23 employees about their work-family boundaries. The first profile includes individuals who allow work in life domains but keep family contained, while the second profile includes individuals who allow family into the work domain but keep work contained (Ammons 2013).

Our second research question was to what extent the profiles identified on the basis of being able and willing to be flexible with work and family boundaries would differ in terms of the level of work-to-family conflict and enrichment. Our findings showed that, after controlling for age, gender, having children under 18, length of tenure, and weekly working hours, the experience of either a negative or positive work-family interface was related to how individuals managed boundaries around their work and family domains. In both samples, segmentors experienced the highest level of work-to-family conflict and lowest level of work-to-family enrichment, whereas integrators reported the highest level of work-to-family enrichment and the lowest level of work-to-family conflict. Our results are consistent with findings of Bulger et al. (2007), who found that setting more flexible and permeable boundaries around work and family domains was related to higher work-family enrichment. It is noteworthy that the segmentors and favoring family over work profiles, who worked fewer hours than integrators, were more likely to experience work-to-family conflict.

Our finding that integrators reported a higher level of work-to-family enrichment and less work-to-family conflict than segmentors is, however, inconsistent with our second hypothesis (H2) and some previous studies (Chen et al., 2009; Li et al., 2013). One explanation for this particular result could be that, since work can be a source of fulfilment (Csikszentmihalyi \& LeFevre, 1989), employees might increase rather than decrease the positive aspects of work by integrating work and family domains (Ilies, et al., 2009). In this way, our present findings differ from those of Chen (2009), Desrochers et al. (2005), Li et al. (2013), and Ilies, et al. (2009) who conversely concluded from their findings that an increase in switching between roles actually has a negative impact on people's work-life 
balance, and that minimizing this is thus more beneficial. One possible explanation for the inconsistency of these results is that most of the other studies have been done in the US, where cultural norms concerning the primacy of the work role differ, and an individualistic approach to work-family issues predominates (Bulger et al., 2007; Kossek, et al., 2012). In Nordic countries such as Finland, however, the dual-earner family model receives much greater support by the state; there is good and affordable daycare provision for children, care for the elderly, paid parental leave, and care entitlements (Korpi, 2000). These all help families to manage the work and family interface more easily (see Abrahamsen, Holte \& Laine, 2012). In this respect, integrators may thus be in a better position to experience more enrichment than conflict in Nordic countries.

One methodological aim of the present study was to assess the factor structure of the work-family-flexibility scale using confirmatory factor analysis (CFA) in two samples of Finnish professionals, and in this respect we succeeded. The four-factor structure we hypothesized, with two flexibility factors of willingness and ability each for work and family, provides additional evidence of reliability and construct validity for the scale originally developed in the US by Matthews and Barnes-Farrell (2010). It shows that this scale can also be used in a Nordic context.

\section{Implication and Limitations}

Our findings suggest that the more able and willing people are to integrate the domains of work and family, the more enrichment and less conflict they experience between work and family domains. Hence, these findings are important for developing organizational policies that increase the ability for work-family role integration when employees are willing to do so (Ilies, et al., 2009). As boundary management styles seem also to be occupation-specific to some extent, organizations should think how they can be more sensitive to employees' boundary management preferences in different kinds of work situations. Work-family balance is achieved when employees' preferences for integration or segmentation (or combinations thereof) are taken into account. It is also worth noting that other factors highlighted by our study, such as the age of children, may affect these preferences too. This points to the need for longitudinal research in future to explore the a desire for segmentation or integration, and also enactment of boundary management strategies when the work and family environment is changing over time (e.g. getting a job promotion, having a divorce)There are four major limitations to the present study. First, because our research design is cross-sectional, the relationships between variables do not necessarily imply causation. Second, the present study used self-report questionnaires to examine boundary-flexibility, conflict, and enrichment between work and family domains; and these may be prone to a response bias towards what participants think are socially desirable outcomes (Polit \& Beck, 2012). Third, the sample consisted solely of university employees and nurses, restricting the generalizability from these findings to other occupational groups, such as blue-collar employees. Given the flexibility and relative control over working hours that university employees (especially academics) have, the results of the present study best represent work places that are also characterized by relatively high flexibility and control over one's work. Moreover, nurses in Finland, compared to many other countries outside Scandinavia, have better work-family policies which help them to meet the demands of both domains (Thévenon, 2011). Fourth, the present study was carried out in Finland and nowhere else, and results may well be different in countries with a different work-family policy, legislation and culture. For instance, Nordic countries are well-known for their statutory work-family policies, which evidently will have an impact on employees' experiences of the work-family interface (O'Brien, Brandth, \& Kvande, 2007). For our findings to be applicable elsewhere, they therefore need to be tested in other contexts too.

\section{Conclusion}

The present study identified three distinct profiles in both university and nurse samples. Segmentors were characterized by a low level of work-flexibility ability and work-flexibility willingness, but an average level of family-flexibility ability and willingness. Integrators, meanwhile, scored high in all four factors, which means they showed a high tendency to integrate the work and family domains. Integrators in both the university and nurse samples reported more work-to-family enrichment and less work-to-family conflict, while segmentors reported more conflict and less work-to-family enrichment.

\section{Acknowledgement}

This study was funded by a grant from the Academy of Finland (138369) for Johanna Rantanen, and a grant from the department of psychology, University of Jyväskylä for the first author.

\section{References}

Abrahamsen, B., Holte, K. A., \& Laine, M. (2012). Work-Family Interference: Nurses in Norway and Finland. Professions and professionalism, 2, 60-74. http://dx.doi.org/10.4236/ojn.2013.31013 
Allen, T. D., Cho, E., \& Meier, L. L. (2014). Work-family boundary dynamics. Annual Review of Organizational Psychology and Organizational Behavior, $1, \quad 99-121$. http://dx.doi.org/10.1146/annurev-orgpsych-031413-091330

Ammons, S. K. (2013). Work-family boundary strategies: Stability and alignment between preferred and enacted boundaries. Journal of Vocational Behavior, 82, 49-58. http://dx.doi.org/10.1016/j.jvb.2012.11.002

Ashforth, B. E., Kreiner, G. E., \& Fugate, M. (2000). All in a day's work: Boundaries and micro role transitions. Academy of Management Review, 25, 472-491. http://dx.doi.org/10.5465/AMR.2000.3363315

Bulger, C. A., Matthews, R. A., \& Hoffman, M. E. (2007). Work and personal life boundary management: Boundary strength, work/personal life balance, and the segmentation-integration continuum. Journal of Occupational Health Psychology, 12, 365-375. http://dx.doi.org/10.1037/1076-8998.12.4.365

Carlson, D. S., Kacmar, M. K., \& Williams, L. J. (2000). Construction and validation of a multidimensional measure of work-family conflict. Journal of Vocational Behavior, 56, 249-276. http://dx.doi.org/10.1006/jvbe.1999.1713

Carlson, D. S., Kacmar, M. K., Wayne, J. H., \& Grzywacz, J. G. (2006). Measuring the positive side of the work-family interface: Development and validation of a work-family enrichment scale. Journal of Vocational Behavior, 68, 131-164. http://dx.doi.org/10.1016/j.jvb.2005.02.002

Chen, Z., Powell, G. N., \& Greenhaus, J. H. (2009). Work-to-family conflict, positive spillover, and boundary management: A person-environment fit approach. Journal of Vocational Behavior, 74, 82-93. http://dx.doi.org/10.1016/j.jvb.2008.10.009

Clark, S. C. (2000). Work/family border theory: A new theory of work/family balance. Human Relations, 53, 747-770. http://dx.doi.org/10.1177/0018726700536001

Csikszentmihalyi, M., \& LeFevre, J. (1989). Optimal experience in work and leisure. Journal of Personality and Social Psychology, 56, 815-822. http://dx.doi.org/10.1037/0022-3514.56.5.815

Davidson, A. J., Gest, S. D., \& Welsh, J. A. (2010). Relatedness with teachers and peers during early adolescence: An integrated variable-oriented and person-oriented approach. Journal of School Psychology, 48, 483-510. http://dx.doi.org/10.1016/j.jsp.2010.08.002

Desrochers, S., Hilton, J. M., \& Larwood, L. (2005). Preliminary validation of the work-family integration-blurring scale. Journal of Family Issues, 26, 442-466. http://dx.doi.org/10.1177/0192513X04272438

Edwards, J. R., \& Rothbard, N. P. (1999). Work and family stress and well-being: An examination of person-environment fit in the work and family domains. Organizational Behavior and Human Decision Processes, 77, 85-129. http://dx.doi.org/10.1006/obhd.1998.2813

Facca, T. M., \& Allen, S. J. (2011). Using cluster analysis to segment students based on self-reported emotionally intelligent leadership behaviors. Journal of Leadership Education, 10, 72-86. http://dx.doi.org/10.12806/V10/I2/RF4

Frone, M. R. (2003). Work-family balance. In J. C. Quick, \& L. E. Tetrick (Eds.), Handbook of occupational health psychology (pp. 143-162) American Psychological Association.

Greenhaus, J. H., \& Beutell, N. J. (1985). Sources of conflict between work and family roles. Academy of Management Review, 10, 76-88. http://dx.doi.org/10.5465/AMR.1985.4277352

Greenhaus, J. H., \& Powell, G. N. (2006). When work and family are allies: A theory of work-family enrichment. Academy of Management Review, 31, 72-92. http://dx.doi.org/10.5465/AMR.2006.19379625

Hartman, E. (1997). The concept of boundaries in counseling and psychotherapy. British Journal of Guidance and Counseling, 25, 147-162. http://dx.doi.org/10.1080/03069889708253798

Hecht, T. D., \& Allen, N. J. (2009). A longitudinal examination of the work-nonwork boundary strength construct. Journal of Organizational Behavior, 30, 839-862. http://dx.doi.org/10.1002/job.579

Hu, L. T., \& Bentler, P. M. (1999). Cutoff criteria for fit indexes in covariance structure analysis: Conventional criteria versus new alternatives. Structural Equation Modeling: A Multidisciplinary Journal, 6, 1-55. http://dx.doi.org/10.1080/10705519909540118 
Ilies, R., Wilson, K. S., \& Wagner, D. T. (2009). The spillover of daily job satisfaction onto employees' family lives: The facilitating role of work-family integration. Academy of Management Journal, 52, 87-102. http://dx.doi.org/10.5465/AMJ.2009.36461938

Korpi, W. (2000). Faces of Inequality: Gender, Class, and Patterns of Inequalities in Different Types of Welfare States. Social Politics, 7, 127-191. http://dx.doi.org/10.1093/sp/7.2.127.

Kossek, E. E., \& Lautsch, B. (2008). CEO of me: Creating a life that works in the flexible job age (Second printing). Philadelphia: Pearson/Wharton School Publishing.

Kossek, E. E., \& Lautsch, B. A. (2012). Work-family boundary management styles in organizations A cross-level model. Organizational Psychology Review, 2, 152-171. http://dx.doi.org/10.1177/2041386611436264

Kossek, E. E., Baltes, B. B., \& Matthews, R. A. (2011). How work-family research can finally have an impact in $\begin{array}{llll}\text { organizations. Industrial and organizational psychology, 4, 352-369. } & \text { 4 }\end{array}$ http://dx.doi.org/10.1111/j.1754-9434.2011.01353.x

Kossek, E. E., Lautsch, B. A., \& Eaton, S. C. (2005). Flexibility enactment theory: Implications of flexibility type, control, and boundary management for work-family effectiveness. In E. E. Kossek, \& S. J. Lambert (Eds.), Work and life integration: Organizational, cultural, and individual perspectives (pp. 243-261) Lawrence Erlbaum Associates Publishers.

Kossek, E. E., Lautsch, B. A., \& Eaton, S. C. (2006). Telecommuting, control, and boundary management: Correlates of policy use and practice, job control, and work-family effectiveness. Journal of Vocational Behavior, 68, 347-367. http://dx.doi.org/10.1016/j.jvb.2005.07.002

Kossek, E. E., Ruderman, M. N., Braddy, P. W., \& Hannum, K. M. (2012). Work-nonwork boundary management profiles: A person-centered approach. Journal of Vocational Behavior, 81(1), 112-128. http://dx.doi.org/10.1016/j.jvb.2012.04.003

Kreiner, G. E., Hollensbe, E. C., \& Sheep, M. L. (2009). Balancing borders and bridges: Negotiating the work-home interface via boundary work tactics. Academy of Management Journal, 52, 704-730. http://dx.doi.org/10.5465/AMJ.2009.43669916

Li, Y., Miao, L., Zhao, X., \& Lehto, X. (2013). When family rooms become guest lounges: Work-family balance of $\mathrm{B} \& \mathrm{~B}$ innkeepers. International Journal of Hospitality Management, 34, 138-149. http://dx.doi.org/10.1016/j.ijhm.2013.03.002

Matthews, R. A., \& Barnes-Farrell, J. L. (2006). Advancing measurement of work-family boundry management practices. Poster presented at the $21^{\text {st }}$ Annual Conference of the Society for Industrial and Organizational Psychology, Dallas, TX. http://dx.doi.org/10.1016/j.jvb.2010.05.008

Matthews, R. A., \& Barnes-Farrell, J. L. (2010). Development and initial evaluation of an enhanced measure of boundary flexibility for the work and family domains. Journal of Occupational Health Psychology, 15, 330-346. http://dx.doi.org/10.1037/a0019302

Matthews, R. A., Barnes-Farrell, J. L., \& Bulger, C. A. (2010). Advancing measurement of work and family domain boundary characteristics. Journal of Vocational Behavior, 77, 447-460. http://dx.doi.org/10.1016/j.jvb.2010.05

Mauno, S., De Cuyper, N., Tolvanen, A., Kinnunen, U., \& Mäkikangas, A. (2014). Occupational well-being as a mediator between job insecurity and turnover intention: Findings at the individual and work department levels. European Journal of Work and Organizational Psychology, 23, 381-393. http://dx.doi.org/10.1080/1359432X.2012.752896

Nippert-Eng, C. (1996a). Calendars and keys: The classiWcation of "home" and "work". Sociological Forum, 11, 563-582. http://dx.doi.org/10.1007/BF02408393

O'Brien, M., Brandth, B., \& Kvande, E. (2007). Fathers, work and family life: Global perspectives and new insights. Community, Work and Family, 10, 375-386. http://dx.doi.org/10.1080/13668800701574971

Olson-Buchanan, J. B., \& Boswell, W. R. (2006). Blurring boundaries: Correlates of integration and segmentation between work and nonwork. Journal of Vocational Behavior, 68, 432-445. http://dx.doi.org/10.1016/j.jvb.2005.10.006

Polit, D. F., \& Beck, C. T. (2012). Nursing research: Generating and assessing evidence for nursing practice (9th ed.). Philadelphia, PA: Lippincott, Williams, \&Wilkins. 
Rosenzweig, J. M., Malsch, A. M., Brennan, E. M., Huffstutter, K. J., Stewart, L. M., \& Lieberman, L. A. (2011). Managing communication at the work-life boundary: Parents of children and youth with mental health disorders and human resource professionals. Best Practices in Mental Health, 7(1), 67-93.

Rothbard, N. P., \& Dumas, T. L. (2006). Research perspectives: managing the work-home interface. Work-life balance: A psychological perspective. In F. Jones, R. J. Burke \& M. Westman (Eds.), Work-life balance: A psychological perspective (pp. 71-89). Psychology Press.

Satorra, A., \& Bentler, P. M. (2001). A scaled difference chi-square test statistic for moment structure analysis. Psychometrika, 66, 507-514. http://dx.doi.org/10.1007/BF02296192

Thévenon, O. (2011). Family policies in OECD countries: A comparative analysis. Population and Development Review, 37, 57-87. http://dx.doi.org/10.1111/j.1728-4457.2011.00390.x

von Eye, A., \& Bergman, L. R. (2003). Research strategies in developmental psychopathology: Dimensional identity and the person-oriented approach. Development and Psychopathology, 15, 553-580. http://dx.doi.org/10.1017/S0954579403000294

von Eye, A., Bogat, G. A., \& Rhodes, J. E. (2006). Variable-oriented and person-oriented perspectives of analysis: The example of alcohol consumption in adolescence. Journal of adolescence, 29, 981-1004. http://dx.doi.org/10.1016/j.adolescence.2006.06.007 